\title{
Zero crossing and ratio spectra derivative spectrophotometry for the dissolution tests of amlodipine and perindopril in their fixed dose formulations
}

\author{
Paulina Maczka, Anna Gumieniczek ${ }^{*}$, Justyna Galeza, Rafal Pietras
}

Department of Medicinal Chemistry, Faculty of Pharmacy, Medical University of Lublin, Jaczewskiego 4, 20-090 Lublin, Poland

\begin{tabular}{l}
\hline ARTICLE INFO \\
\hline Received 12 June 2014 \\
Accepted 16 July 2014 \\
\hline
\end{tabular}

\section{Keywords:}

amlodipine and perindopril,

fixed dose formulations,

dissolution,

derivative spectrophotometry.

\begin{abstract}
Dissolution tests of amlodipine and perindopril from their fixed dose formulations were performed in $900 \mathrm{~mL}$ of phosphate buffer of $\mathrm{pH} 5.5$ at $37^{\circ} \mathrm{C}$ using the paddle apparatus. Then, two simple and rapid derivative spectrophotometric methods were used for the quantitative measurements of amlodipine and perindopril. The first method was zero crossing first derivative spectrophotometry in which measuring of amplitudes at $253 \mathrm{~nm}$ for amlodipine and $229 \mathrm{~nm}$ for perindopril were used. The second method was ratio derivative spectrophotometry in which spectra of amlodipine over the linearity range were divided by one selected standard spectrum of perindopril and then amplitudes at $242 \mathrm{~nm}$ were measured. Similarly, spectra of perindopril were divided by one selected standard spectrum of amlodipine and then amplitudes at $298 \mathrm{~nm}$ were measured.

Both of the methods were validated to meet official requirements and were demonstrated to be selective, precise and accurate. Since there is no official monograph for these drugs in binary formulations, the dissolution tests and quantification procedure presented here can be used as a quality control test for amlodipine and perindopril in respective dosage forms.
\end{abstract}

\section{INTRODUCTION}

Most of the hypertensive population requires the treatment with two or more antihypertensive agents. Rational combinations in this area are based on agents that either interfere with different pathophysiological mechanisms or effectively block respective responses [8]. An example of synergistic action in this area is the use of the calcium channel blocker, e.g. amlodipine and the angiotensin convertase enzyme inhibitor, e.g. perindopril (Fig. 1).

As far as previous analytical procedures are concerned, some HPLC methods are now available for simultaneous determination of amlodipine and perindopril $[1,3,6,7,12]$. As concerns spectrophotometry, only one method for simultaneous determination of both of the drugs had been described previously [5]. From among the methods mentioned above, only one HPLC method is proposed for the dissolution study of amlodipine and perindopril in their fixed dose formulations [3]. However, to the best of our knowledge

Corresponding author

e-mail: anna.gumieniczek@umlub.pl no spectrophotometric procedure has been described as a suitable tool for this purpose.

Amlodipine

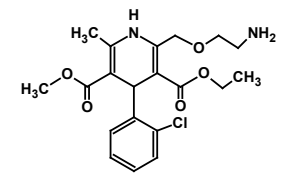

Perindopril

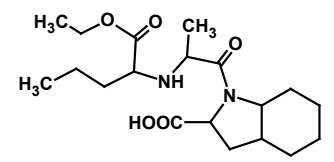

Figure 1. The chemical structures of amlodipine and perindopril

Meanwhile, spectrophotometric methods are still recommended for the dissolution studies because of availability of the instrumentation, the simplicity, speed, precision and accuracy of these techniques [9].

Therefore, the present study was undertaken to prepare new reliable spectrophotometric procedures, which could be useful for quantification of amlodipine and perindopril in their fixed dose formulations, including the dissolution tests. 
These drugs have similar zero order spectra in the UV region (Fig.2), so two derivative spectrophotometric techniques suitable for extracting information from the overlapping bands were proposed $[4,11]$.

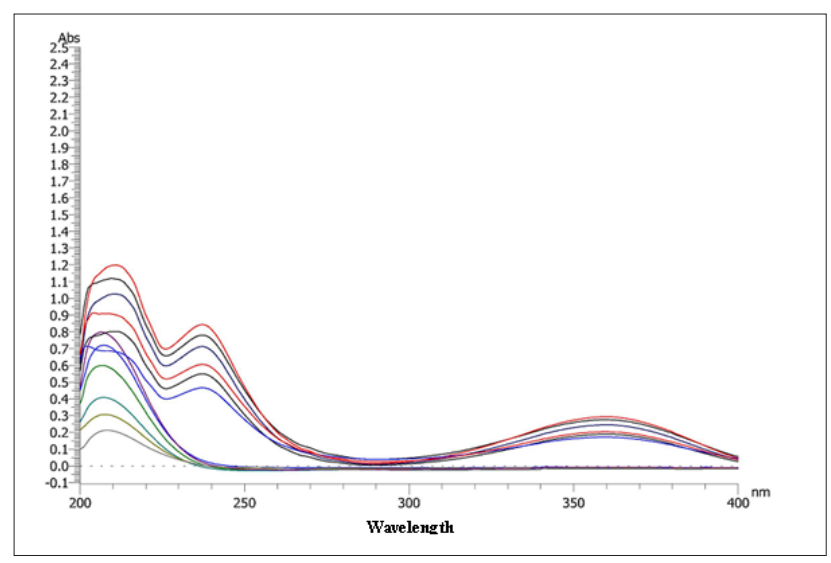

Figure 2. The zero order overlain spectra of amlodipine and perindopril $(2-12 \mu \mathrm{g} / \mathrm{mL})$ in the UV region

\section{MATERIALS AND METHODS}

\section{Materials and reagents}

Amlodipine besylate and perindopril erbumine (tert-butyl amine) pure substances were purchased from Sigma-Aldrich Chemicals (St. Louis, MO, USA). Also, Amlessa ${ }^{\circledR}$ tablets containing $10 \mathrm{mg}$ of amlodipine and $8 \mathrm{mg}$ of perindopril from Krka (Krakow, Poland) were used. The declared excipients for this formulation were: sodium bicarbonate, microcrystalline cellulose, gelatinized mays starch, sodium carboxy methyl starch A, colloidal silica anhydrous and magnesium stearate. Methanol of spectroscopic grade purity was purchased from E. Merck (Germany). All other chemicals were of analytical grade and were supplied by Sigma Chemicals Co. (St. Louis, MO).

Stock solutions of amlodipine and perindopril were prepared by dissolving $10 \mathrm{mg}$ of amlodipine and perindopril in methanol to obtain the concentration of $1 \mathrm{mg} / \mathrm{mL}$. Then, respective dilutions were done using phosphate buffer at $\mathrm{pH}$ 5.5. This buffer was prepared according to the European Pharmacopoeia $7^{\text {th }}$ Edition.

\section{Equipment}

Evolution 6100 dissolution system from Distek Inc. (North Brunswick, NJ, USA) was used for the dissolution studies. The $\mathrm{pH}$ measurements were performed with a model HI9024C of pH-meter from Hanna Instruments (Villafranca Padovana, Italy). Hitachi UV/Vis U-2001 (Tokyo, Japan) double beam spectrophotometer connected to a computer loaded with Hitachi software was used for all spectrophotometric measurements. They were carried out in $1 \mathrm{~cm}$ quartz cells using phosphate buffer of $\mathrm{pH} 5.5$ as blanks.

Stability of amlodipine and perindopril in phosphate buffer of 5.5

Samples of amlodipine and perindopril in phosphate buffer of $\mathrm{pH} 5.5$ were heated in a water bath at $37^{\circ} \mathrm{C}$ under continuous stirring. Respective volumes were taken at the time intervals of 30,60 and $90 \mathrm{~min}$, diluted to gain the concentration over the linearity range and measured in the UV range of 200 to $400 \mathrm{~nm}$.

\section{Calibration}

The stock solutions of amlodipine and perindopril were diluted with phosphate buffer of $\mathrm{pH} 5.5$ to obtain the working concentrations over the range $2-12 \mu \mathrm{g} / \mathrm{mL}$. The absorption spectra of these amlodipine and perindopril mixtures were recorded in the range of $200 \mathrm{~nm}$ to $400 \mathrm{~nm}$ using a bandwidth of $2 \mathrm{~nm}$ and a scan speed of $400 \mathrm{~nm} /$ min. Spectra were stored in the memory of the instrument and transformed to their first derivative with $\Delta \lambda=4 \mathrm{~nm}$ and scaling factor equal 20.

\section{Zero crossing derivative spectrophotometry}

First derivative spectra of amlodipine and perindopril showed that perindopril had zero crossing point at $253 \mathrm{~nm}$ and at this wavelength amlodipine was determined. In turn, $229 \mathrm{~nm}$ was the wavelength suitable for the determination of perindopril (Fig.3). For the preparation of calibration graphs the amplitudes obtained at $253 \mathrm{~nm}$ were plotted against the respective concentrations of amlodipine $(2-12 \mu \mathrm{g} / \mathrm{mL})$ and the amplitudes at $229 \mathrm{~nm}$ were plotted against the respective concentrations of perindopril $(2-12 \mu \mathrm{g} / \mathrm{mL})$.

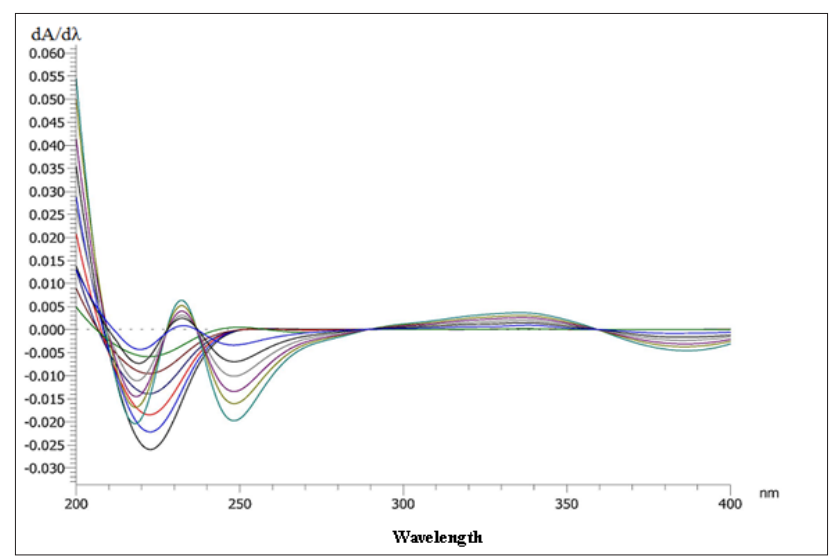

Figure 3. The first derivative overlain spectra of amlodipine and perindopril $(2-12 \mu \mathrm{g} / \mathrm{mL})$ with amplitudes at $253 \mathrm{~nm}$ for amlodipine and $229 \mathrm{~nm}$ for perindopril

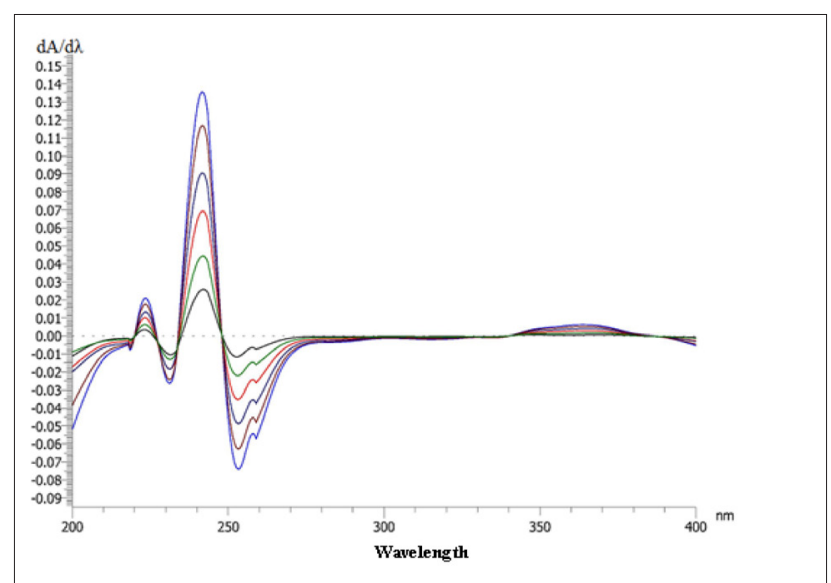

Figure 4. The first derivative spectra of amlodipine over the range $2-12 \mu \mathrm{g} / \mathrm{mL}$ divided by one selected standard spectrum of perindopril $(12 \mu \mathrm{g} / \mathrm{mL})$ with amplitudes at $242 \mathrm{~nm}$

\section{Ratio spectra derivative spectrophotometry}

First derivative spectra of amlodipine over the range 2-12 $\mu \mathrm{g} / \mathrm{mL}$ were divided by one selected standard spectrum of perindopril $(2 \mu \mathrm{g} / \mathrm{mL})$ and then amplitudes at $242 \mathrm{~nm}$ were measured (Fig.4.). Similarly, first derivative spectra 
of perindopril over the range $2-12 \mu \mathrm{g} / \mathrm{mL}$ were divided by one selected standard spectrum of amlodipine $(2 \mu \mathrm{g} / \mathrm{mL})$ and then amplitudes at $298 \mathrm{~nm}$ were measured (Fig. 5).

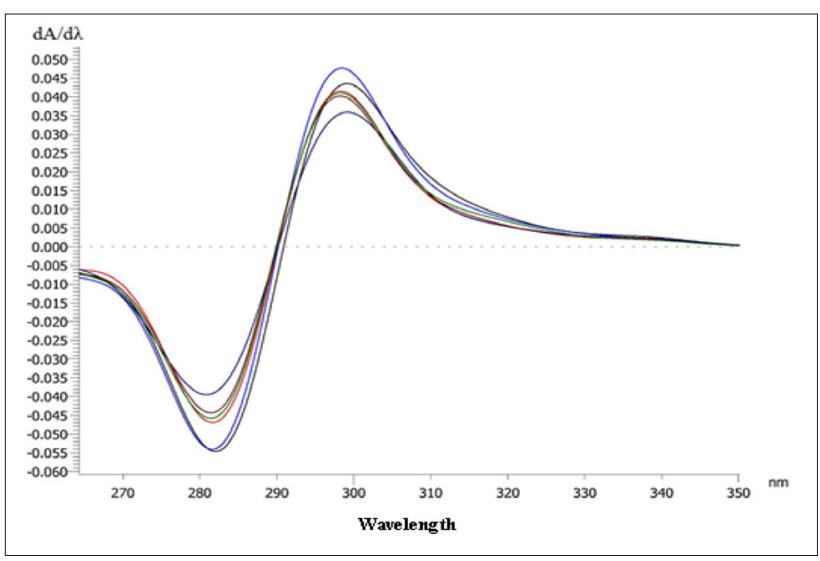

Figure 5. The first derivative spectra of perindopril over the range $2-12 \mu \mathrm{g} / \mathrm{mL}$ divided by one selected standard spectrum of amlodipine $(2 \mu \mathrm{g} / \mathrm{mL})$ with amplitudes at $298 \mathrm{~nm}$

\section{Limit of detection (LOD) and limit of quantification (LOQ)}

For both of the techniques, LOD and LOQ were calculated using the formulas based on SD of the intercept of the respective regression line [10].

\section{Precision}

Precision of the methods was evaluated by analyzing the mixtures of amlodipine and perindopril at three different concentrations 3,7 and $11 \mu \mathrm{g} / \mathrm{mL}$ for both the drugs. These solutions were analyzed three times in the same day (for intra day precision) and over a period of three days (for inter day precision). Finally, the precision was expressed by respective RSD values.

\section{Accuracy in the fortified samples}

The amounts of Amlessa ${ }^{\circledR}$ tablets of ca. $0.1 \mathrm{~g}$ were transferred to $50 \mathrm{~mL}$ volumetric flasks with ca. $30 \mathrm{~mL}$ of methanol, sonicated for $30 \mathrm{~min}$, diluted to the mark with methanol, mixed and filtered by nylon membrane filters $(0.45 \mu \mathrm{m})$. Volumes of $0.8,1.0$ and $1.2 \mathrm{~mL}$ of the filtrates were used to fortify the standard mixtures of amlodipine and perindopril at 80,100 and $120 \%$ levels of fortification. These fortified samples were diluted with phosphate buffer of $\mathrm{pH} 5.5$ to gain the linearity range and analyzed by the described methods.

\section{Assay in tablets}

The amounts of Amlessa ${ }^{\circledR}$ tablets of ca. $0.1 \mathrm{~g}$ were transferred to $50 \mathrm{~mL}$ volumetric flasks with ca. $30 \mathrm{~mL}$ of methanol, sonicated for $30 \mathrm{~min}$, diluted to the mark with methanol, mixed and filtered by nylon membrane filters $(0.45 \mu \mathrm{m})$. Then, $1.5 \mathrm{~mL}$ of the filtered solutions were transferred to $10 \mathrm{~mL}$ volumetric flasks, diluted with phosphate buffer of $\mathrm{pH} 5.5$ and analyzed by the described methods.

\section{Dissolution studies}

The dissolution test was performed using $900 \mathrm{~mL}$ of phosphate buffer of $\mathrm{pH} 5.5$ at $37^{\circ} \mathrm{C}$, in the paddle apparatus with a frequency of rotation equal of $100 \mathrm{rpm}$. The dissolution medium was degassed by heating, filtering and drawing a vacuum for a short period of time. For each $900 \mathrm{~mL}$ of the medium one tablet containing $10 \mathrm{mg}$ of amlodipine and $8 \mathrm{mg}$ of perindopril were used. After 45 min of the test, volumes of ca. $10 \mathrm{~mL}$ of each sample were taken, filtered by nylon membrane filters $(0.45 \mu \mathrm{m})$ and analyzed by the proposed spectrophotometric methods.

\section{RESULTS AND DISCUSSION}

Some chromatographic methods have been reported to date for the simultaneous determination of amlodipine and perindopril in their binary mixtures $[1,3,6,7,12]$. Also one spectrophotometric method has been developed for the same purpose [5]. However, no spectrophotometric procedure has been proposed for the dissolution study of these valuable drugs in their fixed dose formulations. In the present investigation, two different spectrophotometric techniques were elaborated for this purpose. These drugs have similar zero order spectra in the UV region so two derivative spectrophotometric methods suitable for extracting information from the overlapping bands were proposed, i.e. zero crossing and ratio spectra derivative spectrophotometry $[4,11]$.

The instrumental parameters, i.e. smoothing factor $\Delta \lambda$ in the range 2-5 and scaling factor in the range 10-50 were examined during the developing study. Finally, the smoothing factor equal 4 and scaling factor equal 20 were found to be optimum for tracing the first derivatives of the spectra as far as linearity of the methods is concerned. The scan speed was optimized in the range $200-1200 \mathrm{~nm} / \mathrm{min}$ and then the speed equal $400 \mathrm{~nm} / \mathrm{min}$ in connection with a slit width equal $2 \mathrm{~nm}$ was used through the work.

Amlodipine spectrum in zero order is overlapped with that of perindopril but first derivative of the spectra could resolve the overlapped peaks using zero crossing technique and measuring of amplitudes at $253 \mathrm{~nm}$ for amlodipine and $229 \mathrm{~nm}$ for perindopril giving satisfactory results for the linearity study (Tab.1).

Also, the ratio spectra derivative spectrophotometric method has been found to be useful in which the amplitudes at 242 and $298 \mathrm{~nm}$ were measured for amlodipine and perindopril, respectively. In this technique, an accurate choice of a divisor standard concentration is fundamental for several reasons, hence we tested the method with various divisor concentrations. It was observed that the standard solution of $2 \mu \mathrm{g} / \mathrm{mL}$ of perindopril was suitable for determination of amlodipine and $12 \mu \mathrm{g} / \mathrm{mL}$ of amlodipine was suitable for determination of perindopril. These divisor concentrations gave the best results in terms of signal to noise ratio and the highest correlation coefficient values for the calibration procedure (Tab.1).

Table 1. The linearity study for amlodipine and perindopril for the zero crossing and ratio spectra derivative methods $(n=6)$

\begin{tabular}{|c|c|c|c|c|c|c|}
\hline \multicolumn{2}{|c|}{ Equation $y=a x+b$} & $\begin{array}{l}\text { LOD } \\
(\mu \mathrm{g} / \mathrm{mL})\end{array}$ & $\begin{array}{c}\mathrm{LOQ} \\
(\mu \mathrm{g} / \mathrm{mL})\end{array}$ & r & $\begin{array}{c}\text { Mandel } \\
\text { testF }\end{array}$ & $\mathrm{p}$ \\
\hline \multicolumn{7}{|c|}{ Zero crossing } \\
\hline Amlodipine & $\begin{array}{c}y=0.00157 x+ \\
0.0008\end{array}$ & 0.32 & 0.96 & 0.9973 & 1.2451 & 0.1369 \\
\hline Perindopril & $\begin{array}{c}y=0.00174 x+ \\
0.0017\end{array}$ & 0.29 & 0.89 & 0.9961 & 1.0236 & 0.1526 \\
\hline \multicolumn{7}{|c|}{ Ratio spectra derivative } \\
\hline Amlodipine & $\begin{array}{c}y=0.01129 x+ \\
0.0016\end{array}$ & 0.27 & 0.81 & 0.9985 & 1.2265 & 0.1357 \\
\hline Perindopril & $\begin{array}{c}y=0.01720 x+ \\
0.0361\end{array}$ & 0.33 & 0.99 & 0.9960 & 1.0059 & 0.1436 \\
\hline
\end{tabular}


In zero crossing method the inter day precision expressed as RSD was from $1.58 \%$ to $0.19 \%$ for the lowest and the highest concentration of amlodipine. The respective values for perindopril were in the range $1.17-0.28 \%$. In ratio spectra derivative method the inter day RSD values ranged from $1.14 \%$ to $0.18 \%$ for amlodipine, and from $1.50 \%$ to $0.28 \%$ for perindopril. Taking together, RSD values obtained for both the drugs and both the methods confirmed that the applied procedures were sufficiently precise (Tab.2).

Table 2. The precision study for amlodipine and perindopril for the zero crossing and ratio spectra derivative methods

\begin{tabular}{|c|c|c|c|c|c|}
\hline \multirow{2}{*}{\multicolumn{2}{|c|}{ Declared $(\mu \mathrm{g} / \mathrm{mL})$}} & \multicolumn{2}{|c|}{ Intra day precision $(n=3)$} & \multicolumn{2}{|c|}{ Inter day precision $(n=9)$} \\
\hline & & \multirow[t]{2}{*}{$\begin{array}{c}\text { Determined } \\
\text { Mean } \pm S D\end{array}$} & \multirow{2}{*}{$\begin{array}{l}\text { RSD (\%) } \\
\text { crossing }\end{array}$} & \multirow[t]{2}{*}{$\begin{array}{c}\text { Determined } \\
\text { Mean } \pm S D\end{array}$} & \multirow[t]{2}{*}{ RSD (\%) } \\
\hline & & & & & \\
\hline \multirow{3}{*}{ Amlodipine } & 3 & $2.51 \pm 0.03$ & 1.19 & $2.53 \pm 0.04$ & 1.58 \\
\hline & 7 & $6.62 \pm 0.02$ & 0.30 & $6.65 \pm 0.03$ & 0.45 \\
\hline & 11 & $10.69 \pm 0.02$ & 0.19 & $10.71 \pm 0.02$ & 0.19 \\
\hline \multirow{3}{*}{ Perindopril } & 3 & $2.54 \pm 0.03$ & 0.79 & $2.56 \pm 0.04$ & 1.17 \\
\hline & 7 & $6.69 \pm 0.01$ & 0.15 & $6.71 \pm 0.02$ & 0.30 \\
\hline & 11 & $10.72 \pm 0.02$ & 0.19 & $10.74 \pm 0.03$ & 0.28 \\
\hline \multicolumn{6}{|c|}{ Ratio spectra derivative } \\
\hline \multirow{3}{*}{ Amlodipine } & 3 & $2.61 \pm 0.02$ & 0.76 & $2.64 \pm 0.03$ & 1.14 \\
\hline & 7 & $6.73 \pm 0.02$ & 0.30 & $6.77 \pm 0.03$ & 0.44 \\
\hline & 11 & $10.84 \pm 0.03$ & 0.18 & $10.86 \pm 0.02$ & 0.18 \\
\hline \multirow{3}{*}{ Perindopril } & 3 & $2.63 \pm 0.02$ & 0.76 & $2.67 \pm 0.04$ & 1.50 \\
\hline & 7 & $6.75 \pm 0.02$ & 0.30 & $6.80 \pm 0.03$ & 0.44 \\
\hline & 11 & $10.85 \pm 0.02$ & 0.28 & $10.89 \pm 0.03$ & 0.28 \\
\hline
\end{tabular}

The analysis of commercially available formulations using the above procedures revealed satisfactory results as evident from the results shown in Table 3. Also, the fortified samples with different concentrations of amlodipine and perindopril were analyzed. The percentage recoveries obtained for each level of fortification are given in Table 4.

Table 3. The results obtained for amlodipine and perindopril in the fortified samples

\begin{tabular}{|c|c|c|c|c|c|}
\hline Drug & $\begin{array}{c}\begin{array}{c}\text { Level of } \\
\text { fortification } \\
(\%)\end{array} \\
\end{array}$ & $\begin{array}{l}\text { Declared } \\
(\mu \mathrm{g} / \mathrm{mL})\end{array}$ & $\begin{array}{c}\text { Determined } \\
\text { Mean } \pm S D \\
(n=3)\end{array}$ & $\begin{array}{l}\text { RSD } \\
(n=3)\end{array}$ & $\begin{array}{c}\text { Recovery } \\
(\%) \\
(n=9)\end{array}$ \\
\hline \multicolumn{6}{|c|}{ Zero crossing } \\
\hline \multirow{3}{*}{ Amlodipine } & 80 & 7.68 & $7.62 \pm 0.04$ & 0.53 & 99.26 \\
\hline & 100 & 9.10 & $9.05 \pm 0.04$ & 0.40 & 99.45 \\
\hline & 120 & 10.52 & $10.48 \pm 0.03$ & 0.29 & 99.59 \\
\hline \multirow{3}{*}{ Perindopril } & 80 & 6.56 & $6.45 \pm 0.05$ & 0.78 & 98.37 \\
\hline & 100 & 7.70 & $7.63 \pm 0.04$ & 0.55 & 99.13 \\
\hline & 120 & 8.84 & $8.80 \pm 0.03$ & 0.29 & 99.51 \\
\hline \multicolumn{6}{|c|}{ Ratio spectra derivative } \\
\hline \multirow{3}{*}{ Amlodipine } & 80 & 7.68 & $7.62 \pm 0.01$ & 0.14 & 98.00 \\
\hline & 100 & 9.10 & $9.06 \pm 0.04$ & 0.08 & 99.37 \\
\hline & 120 & 10.52 & $10.49 \pm 0.01$ & 0.07 & 99.60 \\
\hline \multirow{3}{*}{ Perindopril } & 80 & 6.56 & $6.43 \pm 0.01$ & 0.14 & 98.37 \\
\hline & 100 & 7.70 & $7.65 \pm 0.01$ & 0.09 & 99.13 \\
\hline & 120 & 8.84 & $8.81 \pm 0.01$ & 0.09 & 99.51 \\
\hline
\end{tabular}

All obtained results were homogenic and the $t$ Student test did not show significant differences between them and the declared contents of the drugs. The results were also estimated by calculating the $95 \%$ confidence intervals and checking if the determined amounts were inside them. For both the drugs and both the methods, all contents were in the confidence intervals so our determinations were sufficiently accurate.

Table 4. The results obtained for amlodipine and perindopril determination in Amlessa tablets $(n=6)$

\begin{tabular}{|c|c|c|c|c|c|c|}
\hline Drug & $\begin{array}{c}\text { Declared } \\
(\mu \mathrm{g} / \mathrm{ml})\end{array}$ & $\begin{array}{c}\text { Determined 95\% } \\
\text { Confidence } \\
\text { Interval }(\mu \mathrm{g} / \mathrm{ml})\end{array}$ & $\begin{array}{c}\text { Determined } \\
\text { Mean } \pm \text { SD } \\
(\mu \mathrm{g} / \mathrm{ml})\end{array}$ & $\begin{array}{c}\text { Recovery } \\
\text { Mean }(\%)\end{array}$ & $\begin{array}{c}\text { Student } \\
\text { test } \\
t\end{array}$ & $p$ \\
\hline Zero crossing \\
\hline Amlodipine & 10.65 & $10.67-10.75$ & $10.71 \pm 0.04$ & 100.56 & 4.1948 & 0.009 \\
\hline Perindopril & 8.55 & $8.44-8.52$ & $8.48 \pm 0.03$ & 99.18 & -5.0344 & 0.004 \\
\hline \multicolumn{7}{|c|}{ Ratio spectra derivative } \\
\hline Amlodipine & 10.65 & $10.76-10.86$ & $10.81 \pm 0.04$ & 101.50 & 8.7885 & 0.000 \\
\hline Perindopril & 8.55 & $8.38-8.47$ & $8.43 \pm 0.04$ & 98.60 & -6.8006 & 0.001 \\
\hline
\end{tabular}

All obtained results were homogenic and the t Student test did not show significant differences between them and the declared contents of the drugs. The results were also estimated by calculating the $95 \%$ confidence intervals and checking if the determined amounts were inside them. For both the drugs and both the methods, all contents were in the confidence intervals so our determinations were sufficiently accurate.

The main purpose of the present study was to apply the elaborated methods for the dissolution studies of fixed dose formulations containing amlodipine and perindopril. It is widely accepted that dissolution testing is a very important tool in the pharmaceutical industry for providing valuable information to design new products and to ensure respective drug quality. It is necessary to have such a test for controlling that the dissolution properties are consistent both within a manufactured bath and between bathes. A dissolution test is also a valuable tool in a bioequivalence study of generic products when a similarity of dissolution profiles between the potential generic product and the reference should be demonstrated [2]. According to European Pharmacopoeia $7^{\text {th }}$ Edition, no less than $80 \%$ of the active ingredients of the labeled claim should be dissolved for a conventional oral formulation.

In our experiment, the choice of the dissolution medium was difficult due to differences in chemical properties of amlodipine and perindopril and their low solubility. After many initial tests, phosphate buffer of $\mathrm{pH} 5.5$ was chosen as a compromise for both the drugs. The tablets were treated with $900 \mathrm{~mL}$ of the buffer at $100 \mathrm{rpm}$ as the paddle speed and temperature of $37^{\circ} \mathrm{C}$ during $45 \mathrm{~min}$. These experiments revealed satisfactory results for both the drugs and two elaborated methods as evident from the results shown in Table 5. After dissolution, the percentage recoveries of both the drugs were far above minimal values indicated in official requirements, e.g. European Pharmacopoeia $7^{\text {th }}$ Edition ( $80 \%$ of the label claimed). The results were also estimated by calculating the $95 \%$ confidence intervals and checking if the determined amounts were inside them. For both the drugs and both the methods, all contents were in the confidence intervals so our determinations of the dissolved drugs were sufficiently accurate. 
Table 5. The results obtained for amlodipine and perindopril during the dissolution study from Amlessa ${ }^{\infty}$ tablets $(n=6)$

\begin{tabular}{|c|c|c|c|c|c|c|}
\hline Drug & $\begin{array}{c}\text { Declared } \\
(\mu \mathrm{g} / \mathrm{ml})\end{array}$ & $\begin{array}{c}\text { Determined 95\% } \\
\text { Confidence } \\
\text { Interval }(\mu \mathrm{g} / \mathrm{ml})\end{array}$ & $\begin{array}{c}\text { Determined } \\
\text { Mean } \pm \text { SD } \\
(\mu \mathrm{g} / \mathrm{ml})\end{array}$ & $\begin{array}{c}\text { Recovery } \\
\text { Mean }(\%)\end{array}$ & $\begin{array}{c}\text { Student } \\
\text { test } \\
t\end{array}$ & $p$ \\
\hline \multicolumn{7}{|c|}{ Zero crossing } \\
\hline Amlodipine & 11.11 & $10.88-11.18$ & $11.11 \pm 0.14$ & 99.28 & 3.8531 & 0.012 \\
\hline Perindopril & 8.88 & $8.58-9.02$ & $8.80 \pm 0.21$ & 99.15 & -0.8739 & 0.02 \\
\hline \multicolumn{7}{|c|}{ Ratio spectra derivative } \\
\hline Amlodipine & 11.11 & $10.95-11.03$ & $10.99 \pm 0.04$ & 98.98 & 1.1299 & 0.041 \\
\hline Perindopril & 8.88 & $8.39-9.21$ & $8.80 \pm 0.04$ & 99.10 & -5.2588 & 0.003 \\
\hline
\end{tabular}

For each component, the results obtained by the proposed methods were statistically compared using the single factor analysis of variance test (one way ANOVA). The calculated $\mathrm{F}$ value did not exceed the critical value for any of the two drugs, indicating that there is no significant difference between the proposed methods (data not shown).

In conclusion, rapid, precise, accurate and specific spectrophotometric methods for the simultaneous determination of amlodipine and perindopril in combined pharmaceuticals were elaborated. The minimum sample preparation, speed of analysis and low cost are the main advantages of these methods when compared to other methods such as HPLC.

\section{REFERENCES}

1. Bhaskara Raju V., Lakshmana Rao A.: Simultaneous estimation of perindopril and amlodipine in combined dosage form by RP-HPLC method. Int. J. Chem. Sci., 9, 1290, 2011.
2. Graffner C.: Regulatory aspects of drug dissolution from a European perspective, Eur. J. Pharm. Sci., 29, 288, 2006.

3. Gumieniczek A. et al.: New HPLC method for in vitro dissolution study of antihypertensive mixture amlodipine and perindopril using an experimental design, Cent. Eur. J. Chem., 11, 717, 2013.

4. Hajian R., Afshari N.: The spectrophotometric multicomponent analysis of a ternary mixture of ibuprofen, caffeine and paracetamol by the combination of double divisor-ratio spectra derivative and H-point standard addition method. E-J. Chem., 9, 1153, 2012.

5. Nayak S.P., Pillai S.: Simultaneous estimation of amlodipine besylate and perindopril erbumine by UV spectrophotometric method. Res. J. Pharm. Technol., 4, 735, 2011.

6. Pattan S.R. et al.: Analytical method development and validation of perindopril erbumine and amlodipine besylate in bulk and tablet dosage form by HPLC. Indian Drugs, 50, 32, 2013.

7. Prajapati J. et al.: Analytical method development and validation of amlodipine besylate and perindopril erbumine in combine dosage form by RP-HPLC. Int. J. PharmTech. Res., 3, 801, 2011.

8. Ram C.V.S. et al.: Comparative effectiveness analysis of amlodipine/ renin angiotensin system blocker combinations. J. Clin. Hypertens., 14, 601, 2012.

9. Rojas F.S., Ojeda C.B.: Recent development in derivative ultraviolet/ visible absorption spectrophotometry: 2004-2008 A review, Anal. Chim. Acta, 635, 22, 2009.

10. Walash M.I., Rizk M.S., Sheribah Z.A., Sheribah Z.A., Salim M.M.: Derivative spectrophotometric analysis of benzophenone (as an impurity) in phenytoin, Chem. Cent. J., 5, 85, 2011.

11. Youssef R.M., Maher H.M.: A new hybrid double divisor ratio spectra method for the analysis of ternary mixtures, Spectrochim. Acta Part A, 70, 1152, 2008.

12. Zaazaa H. E., Abbas S.S, Essam H.A.M., El-Bardicy M.G.: Validated chromatographic methods for determination of perindopril and amlodipine in pharmaceutical formulation in the presence of their degradation products, J. Chromatogr. Sci., 51, 533, 2013. 